\title{
VIAJANTE DO PASSADO / TURISTA DE HOJE: DO ENCONTRO DO OUTRO À DESCOBERTA DE SI PRÓPRIO
}

\author{
Christine Escallier
}

\begin{abstract}
RESUMO
O facto turístico é um facto social total - com dimensões económicas, culturais, sociais, políticas - complexo e antigo. Começou, assim poderíamos dizer, quando o indivíduo se afastou da sua aldeia, da sua cidade, para dormir, pelo menos uma noite, num lugar que não the era familiar. Esta definição não faz, no entanto, a diferença entre o viajante especialista - explorador, aventureiro, missionário e filósofo dos séculos das Luzes, etnólogo, arqueólogo, escritor e pintor do século XIX - e o viajante lúdico, o turista do século XX. Este artigo trata das motivações de quem se desloca: encontro do outro, busca por si mesmo, procura de uma identidade. Através de citações literárias, procura-se conhecer como se viajava ao longo do tempo, a evolução do perfil do viajante e o que tenderia a se tornar no início do século XXI.
\end{abstract}

\section{PaLAVRAS-Chave}

Descoberta de si; evolução do deslocamento; experiência; turismo; viagem

\section{TRAVELLER OF THE PAST / TOURIST OF TODAY: FROM THE ENCOUNTER OF THE OTHER TO SELF-DISCOVERY}

\begin{abstract}
The phenomenon of tourism is a total social fact - with economic, cultural, social, political dimensions - both complex and old. Tourism may be said to have begin when someone left his/her village, his/her home town, to sleep, at least for one night, in an unfamiliar place. This definition, however, does not clarify the difference between the specialist traveller - explorer, adventurer, missionary and philosopher of the Enlightenment era, or ethnologist, archaeologist, writer and painter of the nineteenth century - and the leisure traveller, the twentieth century tourist. This article deals with the motivations of those who travel: the encounter with the other, the search for self-discovery, the search for identity. With the aid of literary quotations, the article attempts to discern how people have travelled in different epochs, the past evolution of the profile of the traveller and its likely evolution in the early $21^{\text {st }}$ century.
\end{abstract}

KEYWORDS

Evolution of travel; experience; self-discovery; travel; tourism 
Partir para uma região desconhecida, às vezes longínqua, é buscar o novo, a diferença, o contato, uma verdade: "tu seguirás o exílio para poderes dizer a verdade", assevera Nietzsche. Viajar é também confrontar sonhos, que começam assim que se entra numa estação, um porto ou um aeroporto:

infelizmente, esses lugares maravilhosos que são as gares, de onde se parte para um destino longínquo, são igualmente lugares trágicos, pois se ali se cumpre o milagre em virtude do qual os lugares, que ainda não tinham existência senão em nosso pensamento, passarão a ser aqueles em que iremos viver, por essa mesma razão é necessário renunciar, ao deixar a sala de espera, a reencontrar logo o quarto familiar onde estávamos há pouco.

(Proust, 1909, p. 57)

O viajante procura o exílio - "O exílio não é de ontem! O exílio não é de ontem! "Ó vestígios, Ó premissas", Diz o Estranho entre as areias, "cada coisa no mundo é nova para mim!..." (Saint-John Perse, 1960). Esta missão leva-o tanto para o ser exterior - o Outro, terço alóctone - como para o seu interior, o eu-indígena.

Toda a viagem tem, em si, um princípio iniciático: tornar-se socialmente adulto, atualizar os seus conhecimentos, realizar o seu potencial, aprender a fazer escolhas de vida. A jornada acompanha a realização do ser. É educadora e formadora; é viagem de juventude:

Naquele tempo, estava na adolescência

Tinha apenas 16 anos e não me conseguia lembrar da infância

Estava a 16 ooo léguas da minha terra natal

Estava em Moscovo, na cidade dos mil e três campanários e das sete estações

E não me bastavam sete estações e mil e três torres

Porque a minha adolescência era tão ardente e tão louca

Que o meu coração, alternadamente, ardia como o templo de Éfeso ou como

a Praça Vermelha de Moscovo quando o sol se põe. (Cendrars, 1919)'

A viagem também é memória. Memória de outros através de uma abundante literatura de viagens, etnográfica, composta desde o século XVI por navegadores, administradores coloniais, exploradores, missionários, médicos e naturalistas que, escrevendo os seus diários e roteiros de bordo, formaram os primeiros arquivos sobre a alteridade. Memória ainda transportada e difundida por coleções arqueológicas, paleontológicas e etnológicas que permitem apreender, através dos objetos recolhidos, toda uma dimensão humana, os seus marcadores (signos) e produções culturais (arte, técnica, etc.): "memória coletiva das nações: esta assenta no reconhecimento, por parte dos viajantes, dos traços que definem identidades nacionais, tanto nos comportamentos das pessoas encontradas (estereótipos) como nos materiais utilizados (mármores de Carrara vs. mármores gregos)" (Bertrand, 2011).

\footnotetext{
' In La Prose du transsibérien et de la petite Jehanne de France (A Prosa do transiberiano)
} 
A viagem também permite deixar uma marca de si mesmo nos lugares visitados, gravando a sua própria memória, apropriando-se intemporalmente, espiritual ou materialmente (lembrança, graffiti, desenho, fotografia, filme) dos objetos encontrados, observados, visitados, maneira de se lembrar e fixar momentos de um passado que fugiu e que a alquimia da memória permite reativar.

Fenómeno da moda, a viagem turística evolui de acordo com as épocas, desejos e necessidades das sociedades. Fundamentalmente uma elite, os viajantes fazem parte, antes de mais, da aristocracia, tanto social como literária e científica. As viagens de recreio e estudo permitem conhecer homólogos de toda a Europa e mais além. Assim, no século XVIII, os aristocratas britânicos desempenharam papel preponderante no nascimento da arqueologia com a descoberta de Pompeia e Herculano e pela acumulação de objetos de arte.

No século XIX, os viajantes não-profissionais continuam a valorizar a busca do exótico, na aceção etimológica do termo, ou seja, a desenvolver uma atitude cultural de gosto pelo exterior, o estrangeiro, encontrar o pitoresco, a expatriação e uma forma de esquecimento. Escritores, como Chateaubriand, Nerval, Lamartine, Stendhal ${ }^{2}$, valorizam os destinos antigos: Grécia, Egito, Médio Oriente. No prefácio de Les Orientales, Victor Hugo (1829-2000) escreve "tudo se inclina para o Oriente. Lá tudo é grande, rico, fecundo como na Idade Média, este outro mar de poesia". Num colóquio sobre peregrinação literária ao Oriente no século XIX, Moussa sublinha que:

Chateaubriand retoma a tradição medieval de peregrinações à Terra Santa, mas também inventa uma viagem cultural ao redor da bacia do Mediterrâneo Oriental. Associando à visita do Santo Sepulcro, em particular a do Pártenon e das Pirâmides, sacraliza as ruínas das grandes civilizações passadas das quais a França Imperial entende ser a herdeira. (Moussa, 2007)

Outros escolheram terras distantes, como o escritor norte-americano Jack London ${ }^{3}$, na Austrália, e mais tarde a exploradora francesa Alexandra David-Néel, no Tibete. Aos escritores juntam-se os pintores-viajantes, principalmente franceses e britânicos, que atravessam o Oriente, onde se verifica a presença colonial ou comercial do seu país. Assim, desde o final do século XVIII e início do século XIX, eles viajam muitas vezes em missão científica, militar, comercial ou diplomática: Flandin na Pérsia, Delacroix em Marrocos e Argel, Matisse na Itália, Alemanha, Argélia, Rússia, Estados Unidos e Polinésia. É também nesta época que o turismo moderno nasce, nomeadamente com a criação da primeira agência de viagens pelo britânico Thomas Cook em $1841^{4}$.

Paradoxalmente, temos de esperar por 1850, ano do primeiro estudo de campo, com o antropólogo norte-americano Lewis H. Morgan, seguido de Boas (1896) e suas

\footnotetext{
${ }^{2}$ Itinerário de Paris a Jerusalém de Chateaubriand, 1811. Viagem ao Oriente de Nerval, 1851. As memórias da juventude de Lamartine, 1863. Memórias de um turista de Stendhal, 1838.

3 O escritor americano embarcou em uma viagem à volta do mundo a bordo do navio Snark e alcançou à Austrália.

4 Thomas Cook organiza para turistas britânicos o primeiro circuito turístico em toda a Europa. Em 1868, criou o voucher de hotel; em 1869, o primeiro cruzeiro no Nilo; em 1874, o cheque viagem. Vendeu as passagens para a viagem a bordo do Titanic em 1912.
} 
expedições norte-americanas, e o britânico Haddon na Nova Guiné (1899), para ver os cientistas imitarem intelectuais e artistas. De facto, até essa data, são essencialmente estudos denominados "de gabinete" que os antropólogos publicam, baseados na literatura de viagens, ao longo dos séculos. O século XX torna-se, no entanto, o de todas as viagens, convidando a explorar e escrever sobre o mundo. Em 1917, a obra de Malinowski (Os Argonautas do Pacífico Ocidental) impôs uma rutura e nova forma de abordagem das relações entre o observador e o observado, na prática de campo e no olhar etnográfico. A tradição do trabalho intensivo de campo remonta a essa publicação, na qual o autor desenvolve metodologia e teoria antropológicas, estabelecendo o conceito de observação participante, ou seja, o imperativo de conviver com os autóctones para os conhecer melhor. Esta nova maneira de se aproximar e trabalhar no terreno será a marca registada de uma geração de etnólogos, constituída por Mead em Samoa (1925-29), Evans-Pritchard no Sudão (1930), First nas Ilhas Salomão, Griaule em Mali (1931-48), Lévi-Strauss no Brasil (1936-38), para citar apenas os precursores. Estes escritos - monográficos ou literários - permitem-nos avaliar não só a variedade, extensão e riqueza do corpus literário dos relatos de viagens, mas também proporcionam uma visão para o conhecimento do mundo (Hambursin, 2005).

$\mathrm{Na}$ análise diacrónica de viagens e viajantes, observa-se a comutação entre viajantes profissionais e turistas. É quando os americanistas e orientalistas retornam às suas terras nativas que os viajantes lúdicos optam por exportar a sua curiosidade, percorrendo os passos dos seus antecessores. Esta reversão torna mais difícil a distinção entre o viajante amador e viajante profissional, o turista ordinário e o turista aristocrático (Sollers, 2004). A confusão ocorre, quando o turista, buscando algures, tende a se comportar como o etnólogo no terreno, em busca de conhecimentos e descobertas. Mas nos primeiros sítios de vilegiaturas, que aparecem em França, no final do século XIX, prefigurando os Villages (Club Méditerranée) criados no mundo no início da década de 1950, o expatriado não está em contacto com o nativo. Instalado em paraísos formatados, vivendo aventuras artificiais e programadas, reproduz os seus ritos, especialmente as suas práticas alimentares. No entanto, "Para amar um país tem que comê-lo, bebê-lo e ouvi-lo cantar", afirma o académico francês Michel Déon (1995). Viaja-se, mas não se vê nada, observava já Séneca no seu tempo: "para que serve viajar, uma vez que sempre te levas contigo? Tens de mudar de alma, não de clima". Esta evocação do turismo é, entretanto, redutora, porque, ao mesmo tempo, o Oriente se abre culturalmente e politicamente ao Ocidente (Índia, Tibete, Nepal), traçando novos caminhos utópicos (Katmandu) que uma geração de hippies segue à procura de uma identidade mística. Os viajantes profissionais, por seu lado, voltam para os territórios "indígenas" (de acordo com a etimologia latina do termo: "natural do lugar") em busca de um novo olhar antropológico, um novo conceito do Outro e de alteridade: aquele que se encontra em casa (conceito de anthropology indigénius).

Nascida após a Segunda Guerra Mundial, a antropologia nacional teve por missão ajudar na reconstrução da imagem de cada nação. Os antropólogos trabalham então, maioritariamente, no seu país. A antropologia indigénius (endo-etnologia, insider 
anthropology) indica a proximidade, a implicação, mesmo a afinidade (cultural, linguística, social ou profissional) do pesquisador com seu campo de estudo, tal Pascal Dibie, etnólogo do interior, e o seu Village retrouvé (1979).

Esta antropologia "caseira" (centrípeta segundo Geertz.) conduz a uma redefinição dos conceitos de viagem e de viajante especialista, complicando, mais uma vez, a tentativa de diferenciação entre viagem e turismo. Se o critério de distinção não for mais geográfico - ou seja, dependendo da distância percorrida - talvez haja necessidade de se interrogar sobre as finalidades de cada um. O que procura o viajante e o que pede ou exige o turista?

É certo que o turismo nem sempre existiu e este fenómeno sociocultural excecional - inventado por etapas - não se reduz a uma migração ou um produto entre outros (Boyer, 2005). De acordo com Amirou (1995), a "viagem turística" é um encontro entre um imaginário turístico e uma viagem interior do turista. O imaginário turístico caracterizar-se-ia por uma busca de autenticidade e fruição estética, entre o lúdico e o didático (Canesse, 2002, p. 307). O estatuto de viajante e de turista seria, por conseguinte, subjetivo, em fronteiras indecisas. Além disso, basta recordar que Marc Boyer e Claude Lévi-Strauss (1996, p. 46) viam em Jean-Jacques Rousseau, respetivamente, o primeiro turista e o primeiro etnólogo-etnógrafo. Essa dupla identidade revela-se apropriada para caracterizar o interesse manifestado pelo filósofo, tanto pelas viagens de estudo como pelas atividades de lazer, num objetivo comum: o da descoberta. "Quando se quer estudar os homens, é preciso olhar perto de si; mas para estudar o homem, é preciso aprender a dirigir a vista para longe; é preciso, primeiro, observar as diferenças para descobrir as propriedades" (Rousseau citado em Lévi-Strauss, 1976, p. 282). Por outras palavras, é necessário reativar por um momento o uso dos olhos para uma leitura do mundo de acordo com Calvino (2014), quando ele mostra a sua personagem em Collection de sable (1984), que rotula garrafas de areia, reavivando assim em sua memória as sensações de uma praia.

Muitas vezes associado aos lazeres (descoberta do território/excursão, divertimento e desporto), descanso (férias laborais) e busca de bem-estar (turismo balneário, termalismo, clubes, spa), o turismo do século XX evolui com as principais mutações económicas, tecnológicas e sociológicas, explorando tanto os desejos das descobertas como as modas, a fim de beneficiar de uma atividade hoje quase acessível a todos, independentemente do status social ou profissional. Assiste-se então a um desenvolvimento sem precedentes de uma mobilidade turística, envolvendo ao mesmo tempo grandes fluxos humanos, culturais e financeiros (Doquet \& Evrad, 2008). Estão a aumentar as estadias no estrangeiro de turistas ocidentais, pelo que se torna necessária uma reestruturação aprofundada da organização das zonas turísticas.

A revolução turística apresenta-se sob a forma de um turismo de massas. Criam-se lugares, práticas, estações lúdicas e de ócio. Sublima-se o mar e o sol, a neve e a montanha, a casa de campo e A mania da vilegiatura 5 .

\footnotetext{
${ }_{5}^{5}$ La trilogia della villeggiatura (1761), de Carlos Goldoni, é uma peça em 3 atos ("Le smanie per la villeggiatura"; "Le avventure della villeggiatura"; "Il ritorno della villeggiatura") descrevendo a burguesia italiana que imita a moda aristocrática e suas migrações de verão em casa de campo.
} 
Viajamos por tantas razões, parecendo improvável enumerá-las exaustivamente: curiosidade, ociosidade, moda, aventura, descoberta, fuga, "apelo das sereias", iniciação, orgulho, romantismo... A partir daí, as motivações tornam-se mais complexas e mergulham as suas raízes na História e nos mitos particularmente alimentados pela literatura: Marco Polo, Ulisses, Jules Vernes, Robinson Crusoe, Gulliver, Tintim... Mas as sociedades modernas esforçam-se, sobretudo, por vender um produto de consumo aos turistas procurando sonhos de exotismo pré-formatados, uma popularização dos exemplares dos patrimónios, uma politização de destinos que lhes ofereçam uma forma de mais-valia da sua imagem social, um ego lisonjeado que desfrutarão ao regresso de viagem:

estou na praia armoricana. Que as cidades se iluminem à noite. Minha jornada está feita; abandono a Europa. A aragem marinha queimar-me-á os pulmões; os climas perdidos tostar-me-ão. Nadar, mordiscar ervas, caçar, fumar, sobretudo; beber licores fortes como metal a ferver - como faziam esses queridos antepassados em volta do fogo. Retornarei com membros de aço, a pela escura, o olhar furioso: por minha máscara julgar-me-ão de uma raça forte. Possuirei ouro: serei ocioso e brutal. As mulheres cuidam destes ferozes enfermos que regressam dos países quentes. (Rimbaud, 1873 , s.p.)

O século XXI marca uma viragem nos comportamentos turísticos. As motivações mudam. Vemos desenharem-se duas tendências fortes: um turismo mais "etnocêntrico" e um mais "solidário" ${ }^{6}$ até mesmo "humanitário". Mas ambas convergem para uma procura única: uma forma de turismo privilegiado, no sentido do raro, do original e não do luxuoso reservado aos ricos.

O exotismo dos séculos passados já não existe. Acabou a era de descobertas de terras desconhecidas e sociedades primitivas excecionais7. Assim fala Marc Augé (1997, p. 13) da viagem impossível "é essa viagem que já não faremos mais, essa que nos poderia ter feito descobrir paisagens novas e outros homens, que nos haveria podido abrir o espaço de novos encontros". Apenas o turismo espacial ainda detém este privilégio ${ }^{8}$, e para O Viajante Imprudente (Barjavel, 1943), as utópicas viagens espácio-temporais que Ihe estão associadas.

Já não há muito para revelar. Temos de reinventar o exotismo, deixá-lo fazer vir até nós, em casa. Este fenómeno é a origem da world music ${ }^{9}$ da década de 1980, que será

\footnotetext{
${ }^{6}$ Excluo aqui uma forma de turismo ligada a negócios (feiras, congressos, convenções...).

${ }^{7} \mathrm{Na}$ densa selva da Indonésia, tribos foram descobertas nas últimas décadas. Em 1993, os Liawep em Papua-Nova Guiné, por missionários; Os Daos, em 1990, por um linguista americano.

${ }^{8}$ Space Adventure, a única empresa que até agora levou os clientes para o espaço (20 milhões de dólares por bilhete), assinou um contrato de exclusividade com a agência espacial russa RFSA (Russian Federal Spatial Agency) para enviar turistas a bordo da estação espacial internacional (ISS). Virgin Galactic, empresa de Richard Branson, foi associada com os criadores de SpaceShipOne, a primeira aeronave privada, para realizar um voo suborbital. Ver www.metrofrance.com/ $\mathrm{fr} /$ article/2007/06/12/15/3919-37/index.xml

9 Ou Música do Mundo, termo genérico usado pelo etnomusicologista no início de 1960 para classificar as músicas tradicionais de cada país. Ao mesmo tempo, a primeira "mistura musical" (música tradicional e atual) foi chamada de
} 
retomada para fins de marketing em benefício das indústrias rotuladas "world" e da moda étnica (desfile de Christian Dior 2009, com suas estatuetas africanas como saltos; as sandálias "picantes" (spicy) de Louis Vuitton; aqueles com sinos (tipicamente do Magrebe) do estilista de origem tunisina Azzedine Alaïa. Nos materiais, procuramos o raro; o píton é atualmente a pele de réptil por excelência, porque evoca terras distantes e selvagens; ou ainda as preciosas madeiras da Indonésia, como teca, para móveis de jardins ocidentais.

Esta moda étnica é partilhada em todos estes aspetos, tanto no planeamento e decoração de interiores (a versão "Safari em casa" por Xavier de Maistre), como no retorno à tatuagem chamada tribal, numa alusão às origens polinésias. Por isso, faz sentido que o turismo siga essa corrente. Música, comida, roupa étnica revelam que os consumidores ocidentais gostam de sonhar com outros lugares. O fenómeno do world desperta o nostálgico do desconhecido, do autêntico, do original, do inexplorado, do identitário.

Uma gastronomia com sabores "exóticos" convida também a viajar. Isto explica que alguns restaurantes das grandes capitais, como o Archipelago de Londres ${ }^{10}$, ofereçam uma aventura culinária inexplorada (discover an uncharted culinary adventure) com produtos singulares como crocodilo, canguru, búfalo selvagem e pavão ou, para "verdadeiros pioneiros" (truly pioneering), gafanhotos e grilos com alho, escorpiões com molho de chocolate. Não é, portanto, surpreendente encontrar, nos mercados tradicionais das aldeias da Normandia, salsichas de bisonte, de avestruz, cervo, touro...

Desde há uma década, alguns agricultores lançaram-se em criações originais (esturjão na Aquitânia, búfalos no Leste, avestruzes, lamas...). Essas novas fazendas têm objetivos semelhantes: lucros, diversificar e, muitas vezes, associar outras atividades com a agricultura, no contexto do turismo (muitas dessas fazendas podem ser visitadas). Desde as cozinhas tradicionais regionais até à nova cozinha, a gastronomia francesa tem conseguido integrar estes imigrantes". (Lohez, 2002)

Vinda do exterior, a carne de asno brasileira serve para manter os produtos de atração turísticos, tal como a salsicha de burro dita "corsa", charcutaria que agora não tem nada de identitário. Muitas vezes importada já feita da Sardenha, tornou-se uma armadilha para turistas, vendida para fingir que o turista carrega com ele o autêntico ${ }^{12}$, mas, "paradoxalmente, a exotismo dessas novas fazendas (burros da América do Sul) revigora a noção de território regional e a própria imagem da gastronomia francesa" (Lohez, 2002).

\footnotetext{
etno-jazz, música étnica ou folk-rock. A expressão anglo-saxã World Music, da década de 1980, é a fonte de vários fenómenos musicais (por exemplo, música de Fusão Étnica).

${ }^{10}$ Archipelago Restaurant, 110 Whitfield Street London, W1T5ED

11 O autor utiliza a palavra "imigrantes" (...la gastronomie française a très bien su intégrer ces immigrés.) enquanto figura de estilo para designar os produtos vindo de fora.

${ }^{12}$ A tradicional salsicha corsa é feita com porco. A carne de asno foi pontualmente utilizada antes da mecanização ter definitivamente relegado o animal para segundo plano. Nos anos 30, contavam-se mais de 20.000 asnos. Hoje são apenas 1000. Por isso, a carna de asno "corsa" é importada.
} 
Com o turismo perigoso/turismo extremo, já não se trata de ir ao encontro do outro, mas da sua coragem, da sua atividade, do seu valor ou até mesmo da sua superioridade. Estes comportamentos sociais correspondem a um tempo em que os alvos, valores e marcadores de identidade passam despercebidos numa globalização do espaço, uma padronização de ideias e um empobrecimento de referentes culturais.

Este turismo de desafio, de emoção, de perigo, que é medido em função do grau adrenalínico, explora as terras incertas e obscuras do Eu. Extrai no exotismo do seu ser a descoberta do nativo que somos para nós próprios. Seria, portanto, uma forma totalmente nova de exploração, um turismo do máximo de si próprio que consiste em se mostrar a si mesmo e aos outros. Esta nova forma de viajar pretende ser um laboratório de experiências de um turismo centrado na busca do sentido da vida e da superação de limites. Pois não é, como a psicanálise afirma, para buscar ou redescobrir o seu "Eu", mas para ir além deste'3. De acordo com a teoria do exotismo de Victor Segalen (1999), que não é senão a noção do diferente despojada do exotismo fictício, tal como o poeta, impulsionado pela libido sentiendi - o desejo de sentir -, o neoturista quer sentir, sentir-se, despertar os seus sentidos para melhor se perceber, nascer para si mesmo, deixar-se arrastar, naufragar para se erguer e muitas vezes partir para melhor retornar:

não se viaja para se enfeitar de exotismo e anedotas, como uma árvore de Natal, mas para que o caminho vos castigue, enxague, esvazie, como as toalhas surradas pelos detergentes que são dadas com um pedacinho de sabão nos bordéis. (Bouvier, 1996)

Ao mesmo tempo e paradoxalmente, o despertar das consciências vem contrabalançar todas as formas de turismo etnocêntrico (turismo de cannabis; pró-criativo ${ }^{14}$; estético) ou desviante (turismo sexual) e frequentemente mercantil. Assiste-se ao nascimento de um turismo responsável, solidário, um etnoturismo com o objetivo de conhecer, mas também de preservar e compreender através da partilha (vide a renovação dos produtos culturais) ${ }^{15}$. Este é o princípio do agroturismo. Este conceito é um prolongamento do ecoturismo, que incentiva os visitantes a experimentar a vida agrícola in situ. O agroturismo recolhe um apoio importante de pequenas comunidades, porque as populações rurais reconhecem os benefícios do desenvolvimento sustentável, causados por essas formas semelhantes de viagem da natureza. Os visitantes têm a oportunidade de trabalhar nos campos ao lado de agricultores, no espírito do kibutz israelita ${ }^{16}$, ou

\footnotetext{
${ }^{13}$ Em L' Abécédaire de Gilles Deleuze, documentário francês realizado por Pierre-André Boutang, 1988.

${ }^{14} \mathrm{Em}$ 2009, o jornal holandês Trouw publica os resultados de um estudo conduzido pela Associação Europeia para a Reprodução Humana e Embriologia: cada ano, quase 25000 mulheres iriam ao estrangeiro para receber o tratamento contra a infertilidade. Ver www.famili.fr/,le-tourisme-procreatif-en-plein-essor,358,49193.asp -

${ }^{15}$ Em 1987, realizei pelo Centre d'Étude des Techniques Traditionnelles Alimentaires um inventário do património culinário no Sul da França (Alpes-Côte d'Azur) no âmbito do Programa de Apoio ao desenvolvimento agro-alimentário. O objetivo era mobilizar parceiros económicos e culturais regionais e nacionais, conscientes do desaparecimento progressivo dos saberes técnicos ligados às terras agrícolas. O estudo revelou uma corrente sociocultural recente e um interesse crescente dos consumidores e profissionais pelos produtos regionais de qualidade. O programa teve o papel de valorizar esses produtos e receitas tradicionais através de diversas ações (Escallier \& Mousse, 1991; Escallier, 2016).

${ }^{16}$ A partir dos anos 1960-70, o kibutz abriu-se para uma forma de turismo, acolhendo trabalhadores judeus e não-judeus e voluntários estrangeiros.
} 
ainda no mar, com os pescadores, segundo o conceito de pescaturismo ${ }^{17}$, abordagens de um turismo solidário e societário.

Em suma, quem é verdadeiramente o viajante-turista? É um consumidor de um produto puramente comercial ou um descobridor de património cultural? Um viajante frívolo, um intruso, um "idiota das viagens" 18 , de acordo com a expressão do antropólogo Jean-Didier Urbain (1991)? Numa hierarquia simbólica, o "turista de elite" gosta de caricaturar o "turista plebeu". Jean Dutourd'9 disse desse último: "Os turistas detestam olhar. A câmara olha em seu lugar. Quando fizeram clique-claque, ficam apaziguados, tinham amortizado a sua viagem. As pilhas de fotos que guardam são como muitos diplomas certificando que eles se deslocaram".

Mas, independentemente do tipo de viagem realizada - viagem-descoberta destinada ao conhecimento geográfico do globo (cartografia do mundo), económico ou guerreiro, realizado pelo gosto de aventura, desafio, périplo literário, artístico, real ou imaginário, peregrinação, excursão, profissionais ou amadores, eruditos ou incultos aquele que a realiza está em um estado de busca, de ciência e conhecimento, de estética ou prazer, ou mesmo de sentido. As razões são numerosas. Mas pode-se dizer que o ser humano é um nómada, nomadismo na origem da conquista da terra, na difusão da cultura e na diversidade dos povos (Attali, 2003; Coppens, 2003). Ele também é um nómada de si mesmo, que se anima a procurar, aqui e além, para encontrar o seu outro: "o verdadeiro domicílio do homem não é uma casa, mas a estrada, e a vida em si mesma é uma viagem a pé" (Chartwin, 2006). Viajar em redor, sem sair do seu quarto (Maistre, $1794 / 2003)^{20}$, ou atravessar os mares a remo, seja qual for a maneira ou a rota tomada - terra, mar, ar -, trata-se sempre de aprendizagem da vida. "A vida é um campo longo para cultivar. Viajar é semear a diversidade da terra. Viajar é embelezá-la das cores do mundo" ${ }^{21}$, ajudando a estabelecer uma sequência ininterrupta entre espaço, tempo e destino. "Viajar é questionar, de repente, a distância o que o tempo só nos poderia dar pouco a pouco" (Morand, 1992).

A viagem promove, portanto, a capacidade de estar em intimidade consigo mesmo. O princípio de, à partida, acreditar que o viajante (etnólogo, explorador, artista), estudioso e especialista, viaja para uma busca do outro, enquanto o turista (veraneante), hedonista e folião, peregrinaria apenas para satisfazer o seu ego, cai rapidamente se aceitarmos que conhecer o outro é aprender sobre si mesmo e inversamente, que não

\footnotetext{
${ }^{17}$ Conceito nascido na Itália, em 1998, através do consórcio PEI (Progetto economia ittica-turismo con i pescatori).

${ }^{18}$ Urbain faz referência a expressão francesa idiot du village (idiota da aldeia) designando uma pessoa estúpida, ignorante, ou sofrendo de doença mental, até demasiada otimista, irrealista. A consonância similar das duas expressões permite a analogia.

${ }^{19}$ Académico, escritor francês (1920-2011).

20 "Meu quarto está situado no quadragésimo quinto grau de latitude (...) sua orientação é entre o levante e o poente; forma um quadrado longo com trinta e seis passos em toda volta, beirando a parede bem de perto. Minha viagem terá, entretanto, mais que isso, porque eu o atravessarei frequentemente ao longo e ao largo, ou mesmo diagonalmente, sem seguir nenhuma regra nem método. Eu farei até ziguezagues, e percorrerei todas as linhas possíveis em geometria, se a necessidade o exigir". Maistre In Viagem ao redor do meu quarto.

${ }^{21}$ Ludovic Lesven, Professor auxiliar, investigador em laboratório de Físico-Química do Ambiente.
} 
se pode representar bem o outro, sem termos já adquirido uma representação de nós próprios. Em suma, uma identidade, uma prova da própria existência.

O desfecho desta reflexão é que a "qualidade" da viagem não seria o valor absoluto. A viagem basta-se a si própria para instruir em si mesma; esta é a ideia mencionada por Georges Kassai (1994), "toda a viagem só tem significado na medida em que se realiza dentro de nós mesmos. Mas tantos vistos, licenças e livres-trânsitos são necessárias para isso" e, para educar sobre os outros, a viagem permite "esfregar e limar o seu cérebro contra o do outro". A experiência da viagem tem, portanto, em si, uma virtude filosófica (reconquista de si próprio, reencarnação), uma virtude epistémica (aquisição de conhecimentos) e uma heurística (descobrir outros lugares e descobrir-se diferente).

\section{CONCLUSÃO: DE VIAGENS EXPLORATÓRIAS AO TURISMO DE LAZER}

"Odeio as viagens e os exploradores". Em uma entrevista ${ }^{22}$, Claude Lévi-Strauss explica o célebre incipit da sua obra Tristes Trópicos (1955): “para o etnólogo, a viagem não é um objetivo: é um meio, um meio indispensável, e o que importa, não é o aspeto turístico, mas o que trazemos de conhecimentos e informações".

Graças aos numerosos estudos de pesquisadores em ciências sociais que partiIham essa visão, podemos dizer que hoje o Ocidente adquiriu uma forma de cultura antropológica. A corrente etnológica tem mostrado, do ponto de vista científico, como olhar para o outro - um olhar mais longe (Rousseau, 1781/2002) - oferecendo uma reflexão filosófica sobre a alteridade e a noção de cultura. O tempo formou o pensamento na noção de diferença, permitindo distinguir o exótico da identidade, ou seja, reconhecer o estranho como ele é - e não como ele imagina que seja ou deveria ser - de acordo com critérios estereotipados ou fantasiados. É também assim para a abordagem turística. Mesmo nos seus exemplos extremos (viagem paixão/viagem exaltação), que se faz atravessando os países em guerra, navegando em águas infestadas de piratas ou empurrando a porta de um Ethnic Restaurant, este passo começa a partir de um desejo do verídico, do real, do próximo. Finalmente, livre das suas representações quiméricas, o Ocidental viajaria para o conhecimento e não para saciar uma forma de voyeurismo etnocêntrico.

Paradoxalmente, e com a abertura de alguns países asiáticos ao turismo internacional ocidental (Birmânia, Butão) e também à cultura ocidental, os países da Europa e da América poderiam acabar por se tornarem um novo exotismo! Pode servir como exemplo, uma observação feita no decorrer de uma visita ao campo de Auschwitz. $\mathrm{Na}$ entrada principal, um grupo de jovens turistas japoneses disparavam as suas câmaras fotográficas, empurrando-se para ficarem na imagem, imitando o $V$ da Vitória em frente de um sinal de aviso de perigo de morte, legendado "Halt! STó|" (Parar!), sem deixar dúvidas sobre o destino daquele que se recusava a obedecer. Esse comportamento era parecido com aquele adotado em frente da Torre Eiffel. Para esta juventude asiática, o campo de Auschwitz era mais um parque da atração do que um lugar da memória da história ocidental, até mesmo da Humanidade (inscrito em 1979 no Património

\footnotetext{
${ }^{22}$ Entrevista concedida ao jornalista Bernard Rapp em 1991.
} 
da Unesco). Tratava-se de um passeio puramente turístico, no pior sentido do termo. Quando regressaram, diriam: "nós fizemos Auschwitz..." como é provável que uma semana antes, tivessem "feito" Roma ou Paris, como um produto consumido.

Então, que devemos responder à pergunta: o turista é um viajante autêntico?

As suas viagens não são políticas nem científicas. O turista desloca-se, atravessa o espaço; penetra-o, acomete-o, às vezes conquista-o, perturba-o sempre, experimenta o espaço, em redor e todo o ser que o atravessa. O turista consome; o viajante é consumido... Um toma, o outro entrega-se. O turista aflora os lugares, muitas vezes ignorando os seus habitantes, suas práticas, seus pensamentos, sua História. O viajante introduz-se no espaço e convive com os seus anfitriões.

Esta imagem estereotipada do turista, o viajante profissional é, em parte, responsável por ela. O antropólogo também foi envolvido na construção dessa imagem. Sempre teve medo de ver o seu campo de investigação invadido por ele, e ainda mais ser confundido/identificado com ele pelos povos indígenas com quem trabalha. Fala-se, então, de uma possível contribuição da antropologia para uma educação turística, mas que visa não só ensinar aos turistas a viajar, mas também ensinar o povo nativo como receber viajantes, a fim de provocar o interesse e o gosto pelo outro, numa reflexão compartiIhada sobre a descoberta de outras culturas, despertando todos os sentidos da viagem: olhar o outro, escutá-lo, falar com ele, senti-lo e, finalmente, tocá-lo. O turista é um ser complicado que pode tomar várias formas de acordo com suas intenções e ambições, e que se desloca sem justificação séria. Como resultado, pode parecer lunático, inconsequente, por vezes caprichoso. Deve-se, no entanto, lembrar que qualquer experiência de vida requer aprendizagem. Viajar aprende-se: “na primeira viagem, descobre-se, na segunda enriquece-se", de acordo com um provérbio Tuaregue. É, provavelmente, à escala do tempo que se mede a diferença entre viajante e turista, profissional e amador da viagem.

\section{REFERÊNCIAS}

Augé, M. (1997). L'impossible voyage, le tourisme et ses images. Paris: Rivages Poche-Petite Bibliothèque.

Amirou, R. (1995). Imaginaire touristique et sociabilité du voyage. Paris: PUF.

Attali, J. (2003). L'homme nomade. Paris: Fayard.

Barjavel, R. (1943/1973). Le voyageur imprudent. Paris: Gallimard

Bertrand, G. (2011). Voyage en Italie et expérience de la mémoire. Les Français face aux découvertes archéologiques. 1750-1815. In S. Moussa \& S. Venayre (Eds.), Le voyage et la mémoire au XIXe siècle. Retirado de http://www.ccic-cerisy.asso.fr/voyageo7.html

Bouvier, N. (1996). Le poisson-scorpion. Paris: Gallimard.

Boyer, M. (2005). Histoire générale du tourisme du XVI au XXle siècle. Paris: L'Harmattan.

Calvino, I (2014). Collection de sable. Paris: Folio-Gallimard. 
Canesse, A.-A. (2002). Rachid Amirou, imaginaire du tourisme culturel. Anthropologie et Sociétés, 26(2-3), 307-308.

Cendrars, B. (1919). Du monde entier (Les Pâques à New York, Prose du Transsibérien et de la petite Jeanne de France, Le Panama ou les Aventures de mes sept oncles). Paris: La Nouvelle Revue française.

Chatwin, B. (2006). Qu'est-ce que je fais là ? Paris: Grasset

Coppens, Y. (2003). L'odyssée de l'espèce. EPA-Hachette.

Déon, M. (1995). Je me suis beaucoup promené... Paris: Gallimard.

Dibie, P. (1979). Le village retrouvé: essai d'ethnologie de l'intérieur. Paris: Aube.

Doquet, A. \& Evrard, O. (Dir.) (2008). Tourisme, mobilités et altérités contemporaines. Civilisations, 57.

Escallier, C. \& Mousse, D. (1991). Pétrir, frire, mijoter: les cuisines des Alpes-du-Sud avec 30 recettes originales. Les Alpes de Lumière, 108.

Escallier, C. (2016). Le pain bouilli (po buli) des montagnards alpins. Techniques et traditions à Villar d'Arêne/ France. Património alimentares de aquém e além-mar. Coimbra: Imprensa da Universidade de Coimbra.

Hambursin, O. (2005). Récits du dernier siècle des voyages: de Victor Segalen à Nicolas Bouvier. Paris: PUF-Sorbonne.

Hugo, V. (2000). Les orientales. Paris: Poche.

Lévi-Strauss, C. (1955). Tristes tropiques. Paris: Plon.

Lévi-Strauss, C. (1976). O pensamento selvagem. São Paulo: Companhia Editora Nacional.

Lévi-Strauss, C. (1996). Anthropologie structurale deux. Paris: Plon.

Lohez, M. (2002). Bisons, esturgeons, autruches... gastronomie exotique de terroir. Cahier Espace, 76.

Maistre, X. de (1794/2003). Voyage autour de ma chambre. Paris: Flammarion.

Morrand, P. (1992). Éloge du repos. Arléa.

Moussa, S. (2007). Le pèlerinage littéraire en Orient au XIXe siècle. Colloque Le voyage et la mémoire au XIXe siècle. 1-8/09/2007. Centre Culturel International de Cerisy-la-Salle, França.

Proust, M. (1919). A l'ombre des jeunes filles en fleurs. Paris: Gallimard.

Rimbaud, A. (1873). Mauvais sang, in Une saison en enfer. Retirado de http://abardel.free.fr/petite_anthologie/ mauvais_\%2osang_3.htm

Rousseau, J.-J. (1781/2002). Essais sur l'origine des langues (Ch. VIII). Retirado de de http://classiques.uqac.ca/ classiques/Rousseau_ji/essai_origine_des_langues/origine_des_langues.pdf

Saint-John Perse (1960). Exil I. Paris: Gallimard.

Segalen V. (1999). Essai sur l'exotisme: une esthétique du divers. Paris: Librairie générale française.

Urbain, J.-D. (1991). L'idiot du voyage : histoires de touristes. Paris: Plon. 


\section{NOTA BIOGRÁFICA}

Etno-Antropóloga, Doutorada em Etnologia pela Université de Paris X-Nanterre Professora auxiliar de nomeação definitiva, Investigadora integrada na Unidade de I\&D CRIA-Center for Research in Anthropology.

Email:chrisesc@uma.pt

Endereço: Universidade da Madeira, Faculdade de Artes e Humanidades, Campus da Penteada 9000-390 Funchal Madeira Portugal

* Submetido: $28-02-2018$

* Aceite: 16-06-2018 